\title{
Off-Gas Treatment of Ammonia Using a Diffused Air Stripper:A Kinetic Study
}

\author{
Hooshyar Hossini, ${ }^{1}$ Abbas Rezaee, ${ }^{1, *}$ Bita Ayati, ${ }^{2}$ and Amir Hossein Mahvi ${ }^{3}$ \\ ${ }_{1}^{1}$ Environmental Health Department, Faculty of Medical Sciences, Tarbiat Modares University, Tehran, IR Iran \\ Environmental Health Department, Faculty of Medical Sciences, Tarbiat Modares University, Tehran, IR Iran
2 Department of Environmental Engineering, Faculty of Civil and Environmental Engineering, Tarbiat Modares University, Tehran, IR Iran \\ ${ }^{2}$ Department of Environmental Engineering, Faculty of Civil and Environmental Engineering, Tarbiat Modares Univ
Environmental Health Department, School of Public Health, Tehran University of Medical Sciences, Tehran, IR Iran \\ ${ }^{*}$ Corresponding author: Abbas Rezaee, Environmental Health Department, Faculty of Medical Sciences, Tarbiat Modares University, Tehran, IR Iran. Tel:+98-2182883575, Fax:+98-2182883575, \\ E-mail: rezaee@modares.ac.ir \\ Received 2015 February 5; Revised 2015 August 16; Accepted 2015 August 26.
}

\begin{abstract}
Background: The presence of excess ammonia nitrogen in aqueous environments has caused various problems such as eutrophication, oxygen depletion and aquatic toxicity. Hence, it is necessary to have special consideration in the discharge of ammonia to environment. Objectives: The aim of this study was to study kinetic of ammonia degasification at a short-time (6 hours) with relatively constant $\mathrm{pH}$ and temperature.

Materials and Methods: Ammonia degassing was carried out using a diffused air stripper. The unit consisted of $1 \mathrm{~L}$ cylindrical column with dimension of $30 \times 8 \mathrm{~cm}$. The flow rate was set at $2 \mathrm{~L} /$ minute at 6 hours. The operating parameters such as ammonia, nitrate, nitrite, electrical conductivity (EC), the oxidation-reduction potential (ORP), and $\mathrm{pH}$ were analyzed according to standard methods.

Results: According to obtained results, the maximum removal efficiencies were determined $17 \%, 35.5 \%, 31 \%, 66 \%$, and $85.5 \%$, for $50,100,200$, 500 and $1000 \mathrm{mg} / \mathrm{L}$ ammonia concentrations, respectively. A first-order kinetic model was adopted to represent the ammonia degassing. Conclusions: The ammonia degassing is a simple and suitable technology for ammonia removal at high concentration. Undesirable removal efficiency (17\%,35.5\% and 31\%) can be occurred in suitable $\mathrm{pH} 11$ in the presence of lower ammonia concentrations (50,100 and 200 $\mathrm{mg} / \mathrm{L})$.
\end{abstract}

Keywords:Ammonia, Wastewater, Removal, Environment Kinetics

\section{Background}

Urbanization, industrialization, and agricultural activities have been entered large quantities of contaminants to the ecosystems and aquatic sources (1). Ammonia has been recognized as a major pollutant in both municipal and industrial wastewater. It exists in various industrial wastewater such as coking, chemical fertilizer, coal gasification, petroleum refining, pharmaceutical and catalyst factories (2). Although ammonia is an essential element for living organisms, it can contribute to the accelerated eutrophication of lakes and rivers, dissolved oxygen depletion, and toxicity in receiving water bodies $(3,4)$. Standard levels of ammonia in surface water have been reported from 0.25 to $32.5 \mathrm{mg} / \mathrm{L}$ (ppm) in the US (5). Permission levels of ammonia concentrations in a mbient air have been recommended by The national institute for occupational safety and health (NIOSH) and The occupational safety and health administration (OSHA) 25 and 50 ppm, respectively. Various processes have been utilized to remove ammonia from water and wastewater such as air stripping, selective ion exchange, break-point chlorination, denitrification, and biological nitrification (6). The biological processes are interested techniques because environmental friendly aspects, but the biological system at higher amounts of ammonia could be failed. Also, it has a toxic effect on the biological population. On the other hand, biological processes (mostly nitrification) could be consumed alkalinity and therefore they need to chemical additives. Production of a large amount of byproducts and undesirable materials are a disadvantage of the proposed methods such as ion exchange and break-point chlorination, which require further costly treatment and handling. Air strippers removed volatile organic chemicals from aqueous solution by providing contact between the liquid and air. The treated air could be released to the atmosphere (7). It offers many advantages such as ability of volatile compounds stripping, low cost and degasification of ammonia at high level concentrations $(8,9)$. A successful air stripping performance depends on some factors that can be asserted as follow: 1) characteristics of the volatile material such as partial pressure, Henry's constant, gas transfer resistance; 2) solution and air temperature; 3 ) turbulence in gaseous and liquid phases; 4) the surface area-to-volume ratio, and (5) striping time $(10,11)$. 
Hossini H et al.

\section{Objectives}

This study aimed to examine the following objectives:

1- To determine the removal efficiency for air stripping at high and low concentrations of ammonia.

2- To demonstrate the high potential of air stripping in upper ammonia concentration.

3- To determine the ammonia volatilization and kinetic constant for diffused system in a short- time (6 hours) with relatively constant $\mathrm{pH}$ and temperature.

4- To Evaluate and determine the ammonia byproducts such as nitrate and nitrite.

5- To trace the oxidation reduction potential and EC variation during air stripping of ammonia.

\section{Materials and Methods}

\subsection{Regents}

All reagents were prepared in analytical grade. An aqueous stock solution of ammonia (from $\mathrm{NH}_{4} \mathrm{Cl}$ salt) was prepared in deionized distilled water. Different concentrations of ammonia were obtained by diluting the stock solution. The $\mathrm{pH}$ was adjusted to the desirable value with $1 \mathrm{M} \mathrm{H}_{2} \mathrm{SO}_{4}$ and $1 \mathrm{M} \mathrm{NaOH}$.

\subsection{Experiment Setup}

The ammonia stripping unit consisted of $1 \mathrm{~L}$ cylindrical column with the dimension of $30 \times 8 \mathrm{~cm}$ using a diffused aerator (HAILEA Aq. Air pump, $5.5 \mathrm{~L} / \mathrm{minute}$ ) in a laboratory scale. Figure 1 illustrates the flow diagram of ammonia air stripping system. Column, ORP/EC/pH meters, the aerator pump and aeration system, thermometer and heater were main components of the proposed system. Air enters through diffusers and rises through the liquid to exit at the top of the column. The ammonia gaseous sample transfers from the water to the air as the bubbles rise through the water. Transfer of the volatile compounds from the water to the air can be improved by increasing the column depth or decreasing the size of bubbles. At all experiments, flow rate was set at $2 \mathrm{~L} /$ minute for 6 hours.

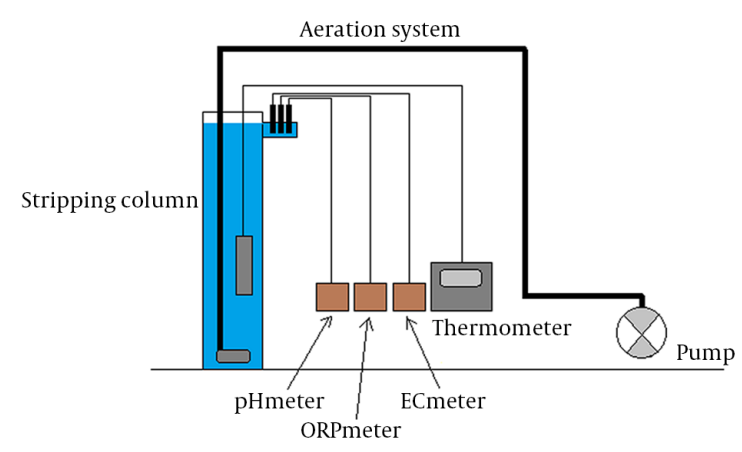

Figure 1. Schematic Flow Diagram of Ammonia Degasification Using Diffused Aeration Air Stripper Systems

\subsection{Analysis}

All experiments were analyzed according to standard methods for the examination of water and wastewater. Nitrate was determined using a spectrophotometer at $\lambda \max 220$ and $275 \mathrm{~nm}$. The nitrite content was analyzed by colorimetric method using sulfanilamide and naphthylethylendiamine di-hydro-chloride regents at $\lambda$ max $543 \mathrm{~nm}$. The determination of ammonia was performed by phenate method $(\lambda \max 640 \mathrm{~nm})$. The $\mathrm{pH}, \mathrm{EC}$ and ORP were measured with a $\mathrm{pH}$ and EC meter and an ORP probe (Eutech).

\section{Results}

\subsection{Effect of Ammonium Concentration and $\mathrm{pH}$}

In this study, ammonia concentrations from 50 to 1000 $\mathrm{mg} / \mathrm{L}$ were considered for the experiments. The overall ammonia removal was presented for $\mathrm{pH}$ values 7 and 11 for 6 hours. It is clear that the better ammonia removal was provided from wastewater during highly alkaline $\mathrm{pH} 11$ for all levels of ammonia. The ammonia degassing was seen with different efficiency during working time and in all ammonia levels (Figure 2). Higher removal efficiency was obtained in pH 11 and higher concentrations of ammonia. Maximum removal efficiency for 50, 100, 200, 500 and $1000 \mathrm{mg} / \mathrm{L}$ were determined about $17 \%, 35.5 \%, 31 \%, 66 \%$ and $85.5 \%$, respectively. In the unadjusted $\mathrm{pH}$, maximum efficiencies of $5 \%, 5.8 \%, 3.7 \%, 2.1 \%$ and $1.7 \%$ were obtained for $50,100,200,500$ and 1000 $\mathrm{mg} / \mathrm{L}$ of ammonia, respectively. The results of ammonium degasification, intermediate byproducts, ORP, EC and $\mathrm{pH}$ are summarized in Table 1.

\subsection{Ammonia Stripping By-Products}

The generation of nitrite during all experiment was not significant. However, nitrate has a remarkable change than nitrite in all concentration levels (Table 1).

\subsection{The Oxidation-Reduction Potential (ORP) and Electrical Conductivity (EC) Variations}

Generally, ORP and EC values were decreased with decrease in $\mathrm{pH}$ values. The ORP values were negative for $\mathrm{pH}$ 11 (Table 1).

\subsection{Kinetic Study}

In the next step, the ammonia degassing rate was determined using first order kinetic for experimental data (Figure 3). Calculated values and constants for various concentrations and pH values are summarized in Table 2.

\section{Discussion}

\subsection{Effect of Ammonium Concentration and $p H$}

Table 2 is shown data for ammonia degasification and other responses when different initial concentrations 
Hossini Het al.

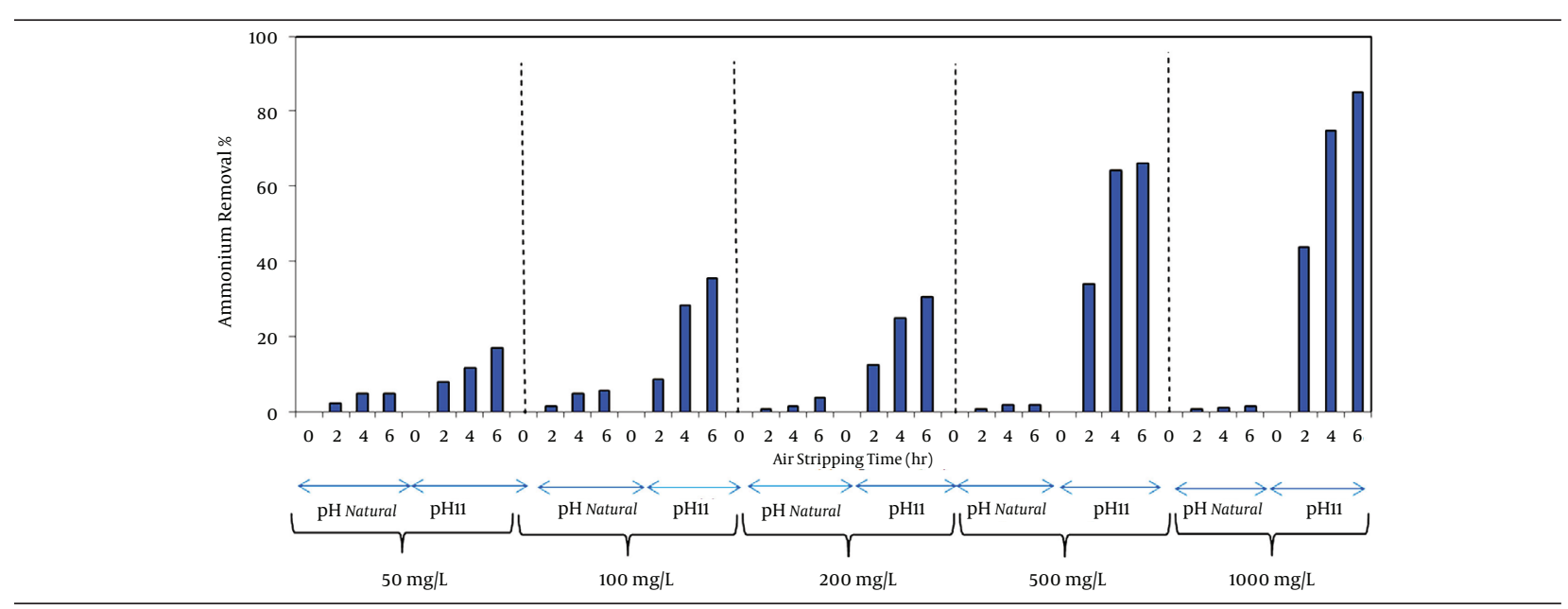

Figure 2. Ammonia Degasification Efficiency During Working Time of 6 hours and Different $\mathrm{pH}$

\begin{tabular}{|c|c|c|c|c|c|c|c|}
\hline Initial Conditions & Time, h & $\mathrm{NH}_{4}$ & $\mathrm{NO}_{2}$ & $\mathrm{NO}_{3}$ & pH & ORP & EC \\
\hline \multirow[t]{4}{*}{$50 \mathrm{mg} / \mathrm{L}^{\mathrm{a}}$} & 0 & 50 & .00 & 0.00 & 8.23 & 1 & 0.45 \\
\hline & 2 & 48.8 & .00 & 0.46 & 7.89 & 29 & 0.43 \\
\hline & 4 & 47.55 & .00 & 0.54 & 7.23 & 56 & 0.43 \\
\hline & 6 & 47.5 & .01 & 0.50 & 7.27 & 89 & 0.41 \\
\hline \multirow[t]{4}{*}{$50 \mathrm{mg} / \mathrm{L}^{\mathrm{b}}$} & 0 & 50 & .01 & 0.00 & 11 & -129 & 1.24 \\
\hline & 2 & 46.05 & .01 & 0.00 & 10.73 & -105 & 1.12 \\
\hline & 4 & 44.11 & .01 & 0.30 & 10.7 & -98 & 1.04 \\
\hline & 6 & 41.47 & .01 & 0.50 & 10.46 & -95 & 1.04 \\
\hline \multirow[t]{4}{*}{$100 \mathrm{mg} / \mathrm{L}^{\mathrm{a}}$} & 0 & 100 & .035 & 1.43 & 7.17 & 56 & 0.81 \\
\hline & 2 & 98.32 & .049 & 3.57 & 7.25 & 93 & 0.87 \\
\hline & 4 & 95 & .053 & 4.2 & 7.35 & 118 & 0.87 \\
\hline & 6 & 94.21 & .055 & 4.38 & 7.36 & 124 & 0.88 \\
\hline \multirow[t]{4}{*}{$100 \mathrm{mg} / \mathrm{L}^{\mathrm{b}}$} & 0 & 100 & .017 & 0.79 & 11 & -65 & 1.51 \\
\hline & 2 & 91.14 & .018 & 0.913 & 10.67 & -30 & 1.37 \\
\hline & 4 & 71.58 & .025 & 1.151 & 10.35 & -29 & 1.32 \\
\hline & 6 & 64.57 & .029 & 1.29 & 10.13 & -17 & 1.42 \\
\hline \multirow[t]{4}{*}{$200 \mathrm{mg} / \mathrm{L}^{\mathrm{a}}$} & 0 & 200 & .007 & 0.63 & 7.66 & 42 & 1.44 \\
\hline & 2 & 198.32 & .010 & 1.3 & 7.32 & 97 & 1.32 \\
\hline & 4 & 196.83 & .017 & 3.4 & 7.3 & 110 & 1.34 \\
\hline & 6 & 192.69 & .050 & 5.14 & 7.23 & 111 & 1.34 \\
\hline \multirow[t]{4}{*}{$200 \mathrm{mg} / \mathrm{L}^{\mathrm{b}}$} & 0 & 200 & .00 & 2.78 & 11 & -220 & 1.74 \\
\hline & 2 & 167.15 & .01 & 3.06 & 10.64 & -180 & 1.70 \\
\hline & 4 & 150.42 & .02 & 5.34 & 10.51 & -138 & 1.67 \\
\hline & 6 & 138.37 & .02 & 7.52 & 10.38 & -110 & 1.67 \\
\hline \multirow[t]{4}{*}{$500 \mathrm{mg} / \mathrm{L}^{\mathrm{a}}$} & 0 & 500 & .029 & 0.00 & 6.94 & 90 & 2.1 \\
\hline & 2 & 495.57 & .03 & 0.32 & 6.85 & 110 & 2.2 \\
\hline & 4 & 490.22 & .046 & 0.75 & 6.8 & 111 & 2.2 \\
\hline & 6 & 489.44 & .062 & 1.03 & 6.73 & 118 & 2.2 \\
\hline \multirow[t]{4}{*}{$500 \mathrm{mg} / \mathrm{L}^{\mathrm{b}}$} & 0 & 500 & .038 & 0.00 & 11 & -112 & 3.5 \\
\hline & 2 & 330 & .050 & 0.36 & 10.84 & -103 & 3.5 \\
\hline & 4 & 178.85 & .052 & 0.78 & 10.64 & -91 & 3.5 \\
\hline & 6 & 170 & .048 & 1.90 & 10.3 & -77 & 3.5 \\
\hline \multirow[t]{4}{*}{$1000 \mathrm{mg} / \mathrm{L}^{\mathrm{a}}$} & 0 & 1000 & .02 & 0.00 & 6.67 & 125 & 6.3 \\
\hline & 2 & 991.31 & .04 & 0.63 & 6.88 & 129 & 6.2 \\
\hline & 4 & 987.46 & .05 & 2.38 & 6.83 & 140 & 6.2 \\
\hline & 6 & 983.04 & .09 & 2.46 & 6.8 & 146 & 6.1 \\
\hline \multirow[t]{4}{*}{$1000 \mathrm{mg} / \mathrm{L}^{\mathrm{b}}$} & 0 & 1000 & .08 & 1.27 & 11 & -129 & 7.2 \\
\hline & 2 & 559.7 & .07 & 2.47 & 10.73 & -105 & 7.2 \\
\hline & 4 & 249.44 & .09 & 3.21 & 10.7 & -98 & 7.2 \\
\hline & 6 & 147.6 & .10 & 3.79 & 10.46 & -95 & 7.2 \\
\hline
\end{tabular}

${ }_{\mathrm{a}}$ Natural $\mathrm{pH}$
$\mathrm{b}_{\mathrm{pH}=11}$ 
Hossini Het al.

\begin{tabular}{lccccc}
\hline \multicolumn{2}{l}{ Table 2. Ammonia Degasification First Order Kinetic Constants } & & & \\
\hline & \multicolumn{2}{c}{ Concentration, $\mathbf{~ m g} / \mathbf{L}$} & $\mathbf{k}$ & $\mathbf{p H} \mathbf{1 1}$ & \\
\cline { 2 - 5 } & .009 & $\mathbf{R}$ & $\mathbf{k}$ & $\mathbf{R}^{2}$ \\
\hline $\mathbf{5 0}$ & .0107 & .905 & .0302 & .985 \\
$\mathbf{1 0 0}$ & .006 & .953 & .0777 & .966 \\
$\mathbf{1 0 0}$ & .0037 & .934 & .0605 & .963 \\
$\mathbf{5 0 0}$ & .0028 & .962 & .1924 & .923 \\
$\mathbf{1 0 0 0}$ & & & .3274 & .994 \\
\hline
\end{tabular}

Figure 3. First Order Kinetic for Ammonia Degasification
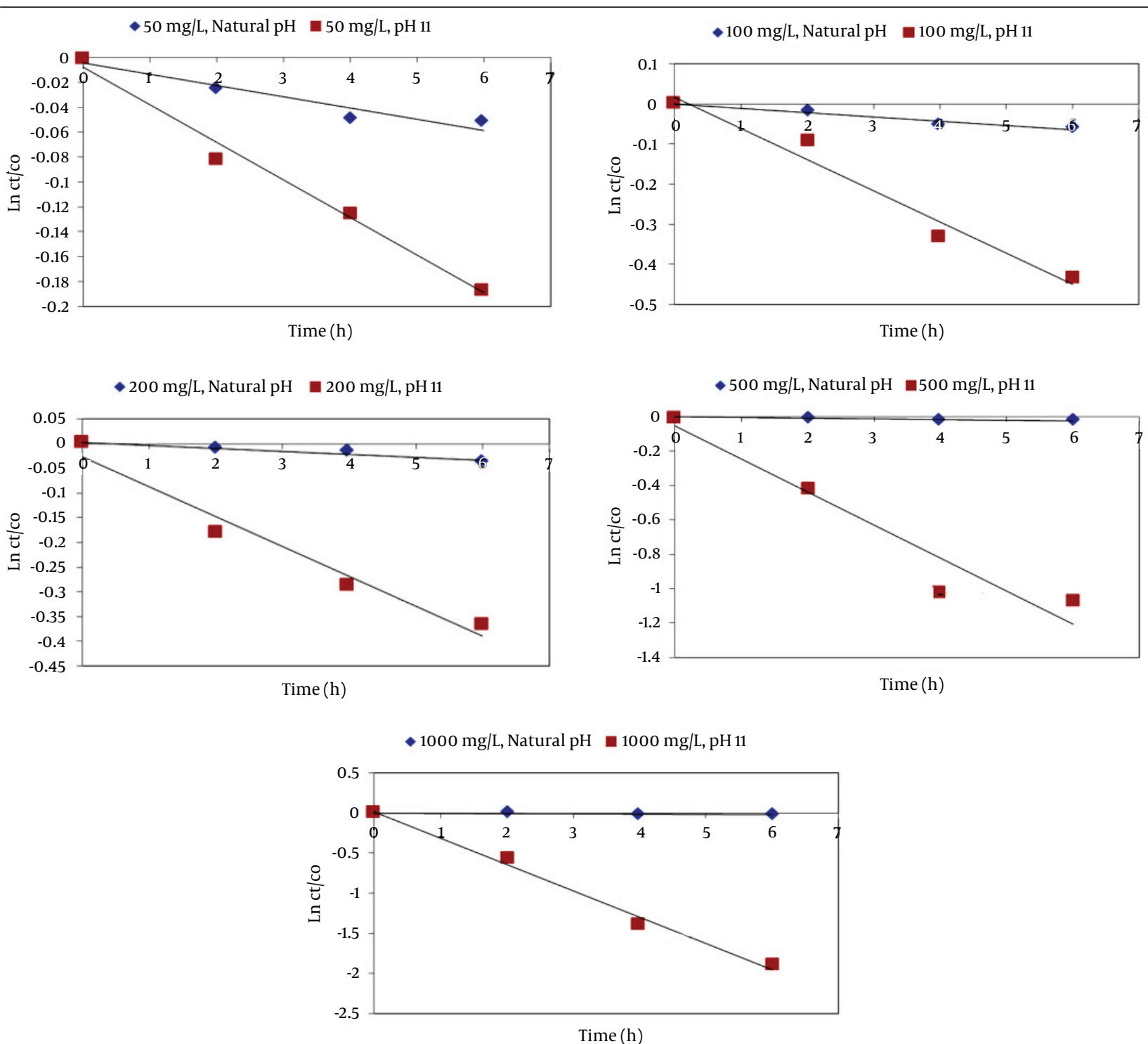

$\mathrm{A}$, Initial concentration $50 \mathrm{mg} / \mathrm{L}$; B, Initial concentration $100 \mathrm{mg} / \mathrm{L} ; \mathrm{C}$, Initial concentration $200 \mathrm{mg} / \mathrm{L}$; D, Initial concentration $500 \mathrm{mg} / \mathrm{L}$; E, Initial Concentration $1000 \mathrm{mg} / \mathrm{L}$.

of ammonium and $\mathrm{pH}$ were used. The results were obtained after 6 hours of constant air loading at $23 \pm 2^{\circ} \mathrm{C}$. According to the obtained results, higher ammonia efficiency was obtained with increase of $\mathrm{pH}$ and concentration (Figure 2). Maximum removal efficiencies for both adjusted (natural $\mathrm{pH}$ ) and unadjusted ( 11) $\mathrm{pH}$ were determined about $17 \%, 35.5 \%, 31 \%, 66 \%, 85.5 \%$ and $5 \%$, $5.8 \%, 3.7 \%, 2.1 \%, 1.7 \%$ from 50, 100, 200, 500 and $1000 \mathrm{mg} / \mathrm{L}$ of ammonia, respectively. Higher efficiency removal at higher $\mathrm{pH}$ can be occurred by displacement ammonium/ammonia equilibrium. The composition of these constituents depends on the $\mathrm{pH}$ and temperature of the 
solution from the following dissociation equilibrium. Therefore, in higher $\mathrm{pH}$ there are greater proportions of the nitrogen in form of ammonia gaseous, and the more percent is stripped (1).

$$
\mathrm{NH}_{4}^{+}+\mathrm{OH}^{-} \rightarrow \mathrm{NH}_{3}+\mathrm{H}_{2} \mathrm{O}
$$

Similarly, other researchers report that the higher efficiency removal of ammonia is achieved at $\mathrm{pH} 11.7$ rather than lower pH during air stripping (7). When the $\mathrm{pH}$ value is adjusted in ranges $11-12$, total ammonium is almost converted into molecular form of ammonia in a solution, and ensuring the air degasification of ammonia. However, the overall performance is dependent on the mass transfer rate of ammonia from water to air (12).

Ammonia degasification first order kinetic constants are shown in Table 2. Accordingly, the first order constant (k) or ammonia loss constant with correlation coefficient $\left(\mathrm{r}^{2}\right)$ was determined for all concentration levels. Additionally, the first order kinetic plots for different ammonia concentration are illustrated in Figure 3. Better the ammonia loss constant with more fitted conformity is observed about 0.3272 /hour and 0.994 for $1000 \mathrm{mg} / \mathrm{L}$, respectively. This fact offers that the mass transfer rate of ammonia from the suspension to air is very high compared to other concentrations. Similar result has been reported that the removal efficiency was increased for ammonia stripping from 80 $\mathrm{mg} / \mathrm{L}$ to $1574 \mathrm{mg} / \mathrm{L}(8)$.

Depending on $\mathrm{pH}$, the ammonia in aqueous solutions is in equilibrium with its protonated forms. However, a given amount of ammonia will be divided between $\mathrm{NH}_{3}$ and $\mathrm{NH}_{4}{ }^{+}$ion, the higher concentration of sum of ammonia species the higher amount of ammonia dissolved in water in ammonia form is present. Because of equilibriums between the gaseous-liquid phases, in saturate solution with air, the gaseous phase will contain some amount of air (this amount will be released form aqueous solution), and the air stream will transport it from the equilibrium. It means the free and summarized $\mathrm{NH}_{3}$ concentration in the solution will be decreased until the limit, where the partial pressure of $\mathrm{NH}_{3}$ above the solution becomes as low that this method becomes ineffective. The equilibrium is dependent to concentration and $\mathrm{pH}$. When we have ammonia in the solution at neutral or acidic conditions, we have not ammonia stripping. The equilibrium is dependent to concentration and $\mathrm{pH}$. When we have ammonia in the solution at neutral or acidic conditions, we have not ammonia stripping ammonia can form $\mathrm{NH}_{4}{ }^{+}$ion in aqueous solutions, therefore if the residual ammonia content is in ammonium ion form, the stripping is not effective.

\subsection{Henry's Law, Mass Transfer and Temperature Dependence}

Air stripping is a mass transfer of volatile compounds that are dissolved in water from the water phase to the air phase. The equilibrium relationship is linear and is defined by Henry's law. For low concentrations of volatile compound a (9):

$$
p_{a}=H_{a} x_{a}
$$

Where, $\mathrm{P}_{\mathrm{a}}$ that is the partial pressure of a gas above a liquid is directly proportional to the mole fraction of the gas $\left(\mathrm{x}_{\mathrm{a}}\right)$ dissolved in the liquid. The $\mathrm{H}_{\mathrm{a}}$ is known as the Henry's constant.

Henry's law constant (HLC) represents, for environmental conditions, the air-water equilibrium partition coefficient for a particular chemical compound presents in a dilute aqueous solution (dilute typically defined as less than 0.001 - 0.01 mole fraction, corresponding to less than 5-50 g/L for a compound with a molecular weight of $100 \mathrm{~g} / \mathrm{mole}$ ) (13). As seen in Table 2, Henry's constant values based on two common units are presented (14).

The value of the constant generally increases or decreases with the liquid temperature. However, the solubility of gases generally decreases with increasing temperature (15). Practical application of the technology for contaminant removal is generally limited to compounds with Henry's constant values greater than 100 atmospheres (9).

In cease of ammonia stripping, if removal efficiency as a function of temperature is related to energy consumption, the best ratio of energy costs/benefits is achieved by keeping the process temperature at $60^{\circ} \mathrm{C}(14)$.

\subsection{Ammonia Stripping By-Products}

The increase in ammonia removal efficiency caused the increased nitrate/nitrite production. Generally, no significant amount of nitrite was produced at all levels. Nitrite $\left(\mathrm{NO}_{2}{ }^{-}\right)$is the unstable form of nitrogen and is easily converted. So, lower amount is seen during air stripping (Table 1). However, more production rates were observed at higher ammonia removal efficiencies.

\subsection{The Oxidation-Reduction Potential (ORP) and Electrical Conductivity (EC) Variations}

Variation data of the ORP via ammonia stripping process are provided in Table 1 . The concomitant decreases in ORP and increases in $\mathrm{pH}$ were observed with increasing the ammonia removal percentage. Variations of ORP were determined in range $-220 \sim-146 \mathrm{mV}$. Generally, low $\mathrm{pH}$ and high ORP create oxidizing conditions whereas high $\mathrm{pH}$ and low (negative) ORP stand for reducing conditions. In this regard, variation of EC was determined, and no significant changes in the amount of EC were exhibited during ammonia degasification time.

\subsection{Limitations of Air Stripping}

Air strippers frequently become fouled by mineral deposits when calcium exceeds $40 \mathrm{mg} / \mathrm{L}$, iron exceeds 
$0.3 \mathrm{mg} / \mathrm{L}$, magnesium exceeds $10 \mathrm{mg} / \mathrm{L}$, or manganese exceeds $0.05 \mathrm{mg} / \mathrm{L}$, or from biological growth. Activated carbon and thermal oxidation are commonly used to treat the off-gas (9). At low concentrations of stripped gaseous, operating costs appear to be equally affected by the mass transfer coefficient of the target compound (16). The costs for removing low concentrations of tetrachoroethylene (TCE) are nearly twice those for removing vinylidine chloride, a compound with a much higher Henry's constant (17).

\subsection{Conclusions}

Based on the results of this study, the following parts can be expressed:

1-The ammonia degassing is a simple and suitable technology for higher concentration of ammonia.

2- Successful ammonia stripping efficiency is dependent on initial $\mathrm{pH}$ and ammonia concentrations.

3- Lower $\mathrm{pH}$ cannot able to remove ammonium ions due to no change in $\mathrm{NH}_{3} / \mathrm{NH}_{4}{ }^{+}$equilibrium.

4- Ammonia and $\mathrm{pH}$ were seen as main affected factors.

5- Undesirable removal efficiency can be occurred in suitable $\mathrm{pH}$ (more than 10.5) in presence of lower ammonia concentration.

6- To remove the lower amounts of ammonia in suitable $\mathrm{pH}$, more time and higher aeration flow are required.

\section{Acknowledgments}

The authors express sincere gratitude to Tarbiat Modares university and Northern Khorasan water and wastewater company for the financial support in this research. Also, we would like to acknowledge Laszlo Kotai from Hungarian academy of sciences for helpful discussion.

\section{Footnote}

Authors' Contribution:All authors participated equally in writing the manuscript.

\section{References}

1. Ghafari S, Hasan M, Aroua MK. Bio-electrochemical removal of nitrate from water and wastewater--a review. Bioresour Technol. 2008;99(10):3965-74. doi: 10.1016/j.biortech.2007.05.026.

\section{[PubMed: 17600700]}

2. Ashrafizadeh SN, Khorasani Z. Ammonia removal from aqueous solutions using hollow-fiber membrane contactors. Chem Eng Journal. 2010;162(1):242-9. doi:10.1016/j.cej.2010.05.036.

3. Lai CL, Chen SH, Liou RM. Removing aqueous ammonia by membrane contactor process. Desalin Water Treatment. 2013;51(25 27):5307-10. doi: 10.1080/19443994.2013.768788.

4. Hossini H, Rezaee A, Ayati B, Mahvi AH. Optimizing ammonia volatilization by air stripping from aquatic solutions using response surface methodology (RSM). Desalin Water Treat. 2015:1-8. doi:10.1080/19443994.2015.1046946.

5. Soltani RDC, Rezaee A, Godini H, Khataee AR, Hasanbeiki A. Photoelectrochemical treatment of ammonium using seawater as a natural supporting electrolyte. Chem Ecol. 2013;29(1):72-85. doi: 10.1080/02757540.2012.704913.

6. Timmer B, Olthuis W, Van Den Berg A. Ammonia sensors and their applications-a review. Sens Actuators, B. 2005;107(2):66677. doi:10.1016/j.snb.2004.11.054.

7. Wang Y, Pelkonen M, Kotro M. Treatment of High Ammonium Nitrogen Wastewater from Composting Facilities by Air Stripping and Catalytic Oxidation. Water, Air, Soil Pollut. 2010;208(14):259-73. doi:10.1007/s11270-009-0164-z.

8. Raquibul A, Md Delwar H. Effect of packing materials and other parameters on the air stripping process for the removal of ammonia from the wastewater of natural gas fertilizer factory. J. Water Resour. Prot. 2009;3:210-5. doi: 10.4236| jwarp.2009.13026.

9. Budzianowski W, Koziol A. Stripping of Ammonia from Aqueous Solutions in the Presence of Carbon Dioxide. Chem. Eng. Res. Des. 2005;83(2):196-204. doi: 10.1205/cherd.03289.

10. Sarioglu M. Removal of ammonium from municipal wastewater using natural Turkish (Dogantepe) zeolite. Sep. Purif. Technol. 2005;41(1):1-11. doi: 10.1016/j.seppur.2004.03.008.

11. Speitel JGE, McLay DS. Biofilm Reactors for Treatment of Gas Streams Containing Chlorinated Solvents. J Environ Eng. 1993;119(4):658-78. doi:10.1061/(ASCE)0733-9372(1993)119:4(658).

12. Quan X, Wang F, Zhao Q, Zhao T, Xiang J. Air stripping of ammonia in a water-sparged aerocyclone reactor. J Hazard $M a$ ter. 2009;170(2-3):983-8. doi: 10.1016/j.jhazmat.2009.05.083. [PubMed: 19540043]

13. Department Of The Army US . Engineering and Design Air Stripping Washington DC: U.S. Army Corps of Engineers; 2001.

14. Sander R. Compilation of Henry's law constants for inorganic and organic species of potential importance in environmental chemistry. Air Chemistry Department Max-Planck Institute of Chemistry. 1999.

15. Staudinger J, Roberts PV.Acritical compilation of Henry's lawconstant temperature dependence relations for organic compounds in dilute aqueous solutions. Chemosphere. 2001;44(4):561-76. doi 10.1016/S0 045-6535(00)00505-1. [PubMed: 11482643]

16. Bonmatii A, Flotats X. Air stripping of ammonia from pig slurry: characterisation and feasibility as a pre- or post-treatment to mesophilic anaerobic digestion. Waste Manage. 2003;23(3):261-72. doi:10.1016/S0956-053X(02)00144-7.

17. Huang JC, Shang C. Air stripping. Advanced Physicochemical Treatment Processes.. New York City: Springer; 2006. pp. 47-79. 